\title{
Influence of the Lung Microbiota Dysbiosis in Chronic Obstructive Pulmonary Disease Exacerbations: The Controversial Use of Corticosteroid and Antibiotic Treatments and the Role of Eosinophils as a Disease Marker
}

\author{
Domenico Maurizio Toraldo ${ }^{\mathrm{a}, \mathrm{d}, \mathrm{e}}$, Luana Conte ${ }^{\mathrm{b}, \mathrm{c}, \mathrm{d}, \mathrm{e}}$
}

\begin{abstract}
Chronic obstructive pulmonary disease (COPD) is a debilitating lung disease associated with loss of lung function, poorer quality of life, co-morbidities, significant mortality, and higher health care costs. Frequent acute exacerbations of COPD are sudden worsening of symptoms, the nature of which is associated with bacterial or viral infections. However, one-third of exacerbations remain of undetermined origin. Although it is largely discussed and controversial, current guidelines recommend treatment of exacerbations with bronchodilators, antibiotics, and systemic corticosteroids; this is despite being associated with limited benefits in term of reducing mortality, side effects and without paying attention to the heterogeneity of these exacerbations. Increasing evidence suggests that the lung microbiota plays an important role in COPD and numerous studies have reported differences in the microbiota between healthy and disease states, as well as between exacerbations and stable COPD, leading to the hypothesis that frequent acute exacerbation is more likely to experience significant changes in lung microbiota composition. These findings will need further examination to explain the causes of lung dysbiosis, namely microbial composition, the host response, including the recruitment of eosinophils, lifestyle, diet, cigarette smoking and the use of antibiotics and corticosteroids. It is now important to assess: 1) Whether alterations in the lung microbiota contribute to disease pathogenesis, especially in exacerbations of unknown origin; 2) The role of eosinophils; and 3) Whether the microbiota of the lung can
\end{abstract}

Manuscript submitted June 25, 2019, accepted July 16, 2019

aDepartment of Rehabilitation, Respiratory Care Unit, ASL/Lecce, Italy bLaboratory of Biomedical Physics and Environment, Department of Mathematics and Physics "E. De Giorgi”, University of Salento, Lecce, Italy "Interdisciplinary Laboratory of Applied Research in Medicine (DReAM), University of Salento, "V. Fazzi" Hospital, Lecce, Italy

${ }^{\mathrm{d} B o t h}$ authors contributed equally to this manuscript.

${ }^{\text {e}}$ Corresponding Author: Domenico Maurizio Toraldo, Department of Rehabilitation, Respiratory Care Unit, ASL/Lecce, Italy. Email: d.torald@tin.it. Luana Conte, University of Salento, Department of Mathematics and Physics "E. De Giorgi”, Lecce, Italy. Email: luana.conte@unisalento.it

doi: https://doi.org/10.14740/jocmr3875 be manipulated therapeutically to improve COPD exacerbation event and disease progression. In summary, we hypothesize that the alterations of the lung microbiota may explain the undetermined origins of exacerbations and that there is an urgent need to facilitate the design of intervention studies that aim at conserving the lung microbial flora.

Keywords: Chronic obstructive pulmonary disease; Lung microbiota dysbiosis; Corticosteroids; Antibiotics; Eosinophils; Probiotics

\section{Introduction}

Chronic obstructive pulmonary disease (COPD) is a progressive lung disease affecting 200 million people worldwide and causes three million deaths each year [1]. COPD includes chronic bronchitis and emphysema, characterized by reduced lung function and prolonged airflow obstruction. Cigarette smoking is the major recognized cause; however, other lung irritants are known, such as air pollution, dust, chemical fumes and genetic predisposition [2]. Although $80 \%$ of patients are smokers, only $15-50 \%$ of smokers develop COPD [3], suggesting other genetic or environmental factors involved.

One of the difficulties in the management of this disease is its heterogeneity in terms of progression, severity, exercise tolerance and symptoms $[4,5]$. This severity is also evident during frequent acute exacerbation of COPD that is a transient period of increased COPD symptoms requiring additional medical treatment and often, hospitalization $[6,7]$. Known subtypes of exacerbations include bacterial or viral infections (54.7\% and $48.4 \%$ respectively) [8], associated or not associated with high eosinophil levels, and these molecular events are typically treated with a combination of antibiotics and corticosteroids in a non-specific manner [6, 9]. Importantly, at least one-third of exacerbations are of undetermined origin [10-12].

The pathogenesis of the progressive airflow limitation in patients with COPD has been related to the innate and adaptive inflammatory immune response of the host [13-15]. However, antigens that drive these responses remain poorly understood. In 2002, Sethi et al have shown that acute COPD exacerba- 
tions were associated with new bacterial strains isolated from sputum and bronchial brushings, and that lungs exhibited extraluminal interactions between bacteria and leukocytes, in particular, alveolar macrophages, suggesting a possible role of bacteria in the pathogenesis of the disease [16, 17]. More recently, bacterial diversity loss was often associated with greater severity of COPD and may be one of the major determinants that influence disease progression and exacerbations.

We hypothesized that change in the lung microbiota due to lifestyle, diet, cigarette smoking and the use of antibiotics and corticosteroids may explain exacerbation cases of undetermined origin and can contribute to examination of COPD complexity and severity. Understanding the causes of lung microbiota alterations may also influence the choice of adequate treatment.

\section{Phenotypes in Acute Exacerbations of COPD}

COPD can no longer be considered as a disease that only involves the lungs, but rather a disease associated with a systemic inflammatory component, which links the disease with other extrapulmonary co-morbidities, such as cardiovascular disorders, skeletal muscle alterations, diabetes, osteoporosis, anxiety, and depression [18, 19]. The great heterogeneity of COPD exacerbations has been widely used to describe and classify the characteristics among patients, with the purpose of identifying different subgroups of patients with a prognostic value that may be screened earlier or that may better respond to therapy. Recently, exacerbation phenotypes were classified according to etiology, inflammatory biomarkers, co-morbidity, clinical manifestation and frequency [19].

The first phenotypical group is based on the etiology of the disease and may have an important therapeutic implication for the appropriate choice of antimicrobial treatment. In particular, some studies highlighted differences in the clinical symptoms, prognosis, and treatment between bacterial infections and viral infections [20]; this latter group commonly shows sore throat, cough, dyspnea [20], higher interleukin 6 (IL-6) levels [21], lower levels of C-reactive protein [22] and longer duration of hospitalization, compared to bacterial infections [23]. On the contrary, a typical symptom in bacterial exacerbations is the purulent sputum due to neutrophil inflammation in both blood and airway [19]. The guideline published in 2011 by the European Respiratory Society recommends avoiding empiric antiviral treatment, except when associated with typical influenza symptoms [24]. The same guideline recommends the use of antibiotics in infections due to bacteria [25].

The second group of exacerbation phenotypes regards inflammation. Patients who manifest exacerbation commonly display heterogeneous inflammatory cells and heterogeneous inflammatory markers. Typical systematic inflammatory markers mainly include C-reactive protein, procalcitonin, serum amyloid A, fibrinogen, and others [19]. Inflammatory cells rather divide patients into four groups: eosinophilic predominant, neutrophilic predominant, paucigranulocytic predominant and mixed granulocytic predominant [26], with different pathological and physiological characteristics [19]. Nota- bly, neutrophilic group poorly responds to standard therapy; whereas eosinophilic group has a better response to corticosteroids [9].

The third phenotype group is based on clinical symptoms that divide exacerbations into three groups [27]. Type 1 includes dyspnea, sputum volume, and purulence; type 2 involves any two of the latter symptoms and type 3 includes one of the latter symptoms combined with cough, wheeze, or others. Antibiotics are recommended for type 1 patients.

The fourth and last phenotype group is based on the frequency of exacerbations. This group includes patients who manifest dynamic lung hyperinflation, increased susceptibility to viral infection, increased extrapulmonary co-morbidities and changes in lower airway bacterial colonization, which is the major argument of this manuscript. Patients who undergo frequent exacerbations have increased systemic and airway inflammation [28, 29], the rapid decline in lung function, worse quality of life [30] and higher mortality [31, 32], compared to patients with no frequent exacerbation. Recommended therapy is long-term inhalation of corticosteroids; anti-inflammatory and anti-infection treatments may be non-therapeutic [19]. However, recommended therapy for frequent exacerbations is bronchial relaxation combined with inhaled corticosteroids [33], in spite of being associated with limited benefits in term of reducing mortality, side effects and without paying attention to the heterogeneity of these exacerbations. In summary, the use of inhaled corticosteroids is very controversial and should be tested with large-scale, randomized, double-blind and controlled studies in order to assess the real effectiveness.

\section{Lung Microbiota and COPD}

The microbiota is defined as the "ecological community of commensal, symbiotic and pathogenic organisms that share our body space" [34]. The bacterial communities that inhabit our environments such as the gut, skin or lung are now appreciated for their role in maintaining tissue, organ and immune homeostasis. Alterations of the resident microbiota have been associated with numerous disorders including cancer, respiratory and cardiovascular diseases as well as obesity [35-39].

Compared to the gut microbiota that is easily accessible by the probe, the lungs and the bronchial tree have been considered sterile in healthy subjects till the last decade, due to the negative cultures obtained from these anatomical sites [40, 41]. Over time, despite the difficulties in the application of these techniques, the new field of culture-independent technique application to the identification of bacteria in the community has shown that lungs are not sterile, in contrast with this historical long-held view [42]. The healthy lung microbiota contains lots of commensal bacteria coming from and shared with the upper respiratory tract and these new results led the nowadaysaccepted knowledge that lower airways contain a consortium that can vary among individuals and across regions [43-45].

The composition of the lung microbiota is determined by the balance of migration of the bacteria from inhalation, mucosal dispersion or micro-aspiration and the microbial elimination by innate and adaptive host defences, cough and mucocili- 
ary clearance [16]. Unlike the gut, the lung is oxygen-rich and it contains lots of lipid-rich surfactants that have bacteriostatic effects against selected bacterial species [46]. In contrast, during disease, the lung environment changes dramatically, creating permissive niches for selective microbial reproduction, leading to the growth of species well-adapted to the injured lung conditions [16]. Alterations in the taxonomic composition are known as dysbiosis and have been associated with the pathogenesis of the lung. Literature reports present differences in the microbiota composition between healthy and COPD states: dominant healthy microbiota is composed of Bacteroidetes phylum that under certain condition, such as disease, shifts towards Proteobacteria, the phylum that contains putative pathogen gram-negative bacteria $[16,47]$. This shift included, besides a significant increase in Hemophilus influenzae (Proteobacteria), a decrease in Veillonella (Firmicutes) and Prevotella (Bacteroidetes).

The lung microbiota also changes during COPD exacerbation conditions compared to stable disease sample [48-50], where the microbial composition shifts toward an abundance of Proteobacteria and decrease in Firmicutes [51]. In particular, Hemophilus influenzae increased [6] whereas the relative abundance of Streptococcus pneumoniae species decreased. In addition, a significant increase of Moraxella catarrhalis was seen between exacerbation versus non-exacerbation samples [51]. Notably, there was a significant positive correlation between Moraxella catarrhalis and the percentage of sputum neutrophils [51], suggesting the possible implication of the host immune response. Other reports have determined colonization by Pseudomonas aeruginosa during exacerbations [47, 52].

Cigarette smoking also contributes to impaired the lung innate immunity through the alterations in ciliary function, mucus, cell phagocytosis and increasing bacterial virulence (e.g. enhanced biofilm formation) $[53,54]$. Notably, the regular exposure to tobacco smoking, which is one of the major causes of COPD, provokes changes of the microbiota in healthy smokers leading to dysbiosis [46]. Smoking damages airway epithelia and epithelial tight junctions causing bronchitis [55]. In addition, smoking is also positively associated with Chron's disease, suggesting further toxic effect on the intestine [56].

\section{Corticosteroids and the Lung Microbiota}

Current guidelines recommend bronchodilators, antibiotics and systemic corticosteroid therapy for acute exacerbations of COPD [57, 58]; this is despite being associated with limited benefits in term of reducing mortality and side effects concerning about the use of corticosteroids for a long term $[58,59]$. There is also a lack of concern about the biological heterogeneity of these exacerbations.

Changes in lung microbiota were also seen during antibiotics and steroids treatment $[51,60]$. These reports assessed a decreased microbial diversity with an increment of Proteobacteria over Firmicutes in patients treated with corticosteroids alone, which corresponded to an increment of Hemophilus influenzae and Moraxella catarrhalis and a decrement of Streptococcus pneumonia [51]. An opposite trend was observed in patients treated with antibiotics (with or without steroids) [51]. Although this latter study and others reported a beneficial role of antibiotics for preventing COPD exacerbations [30, 61-63], a group of researchers recently found an increasing recurrence of Clostridium difficile infections after treating primary infections with antibiotics [64]. All these considerations suggest that it is controversial whether the recurrent use of antibiotics during exacerbations can have adverse consequences on the lung microbiota by driving the loss of diversity that may trigger to a higher risk of other exacerbations or disease progression.

\section{The Role of Eosinophils}

Eosinophils are immune cells from the innate response. These cells were first described by Paul Ehrlich in 1879 [65]. Eosinophils represent less than 5\% of total leucocytes and are innate immune cells formed in the bone marrow. They normally reside in the thymus and gastrointestinal tract $[66,67]$, spending less than $18 \mathrm{~h}$ in circulation [68]. Under certain condition, eosinophils can migrate to tissues acting as inflammatory leading cells, promoting the release of their cytotoxic granular products, chemokines, and cytokines. The role of eosinophilic inflammation is still incompletely understood, although it is widely accepted that their role influences allergic conditions and helminth infection.

Eosinophils are able to reach the lungs, both in healthy and disease states, with incompletely understood role. Increased number of eosinophils has been reported in both central and peripheral airways of COPD patients, detected in the bronchial biopsy, sputum and bronchoalveolar lavage [69]. In the lungs, eosinophils are responsible for augmented endothelial adhesiveness [70] and promotion of humoral immunity, stimulating B cells and type 2 immunity [71]. In addition, the lipid bodies in eosinophils can produce cysteinyl leukotrienes, key mediators in the contractility of bronchial smooth muscle [72]. Interestingly, the cysteinyl leukotriene receptor numbers of the airway mucosal tissue were increased in patients with stable COPD and even more greatly during an exacerbation [73].

Sivapalan et al [74] determined whether blood eosinophil counts could reduce systemic corticosteroid exposure of COPD patients admitted to hospital. They found the noninferiority of eosinophil-guided therapy compared to standard care, with reduction of corticosteroids exposure. Other researchers [75] positively used blood eosinophil levels for predicting response to glucocorticoid treatment and the risk of severe acute exacerbations of COPD patients. Recently, Petite et al [76] evaluated the hospital length of stay (LOS) in hospitalized COPD patients with exacerbations treated with systemic corticosteroid and antibiotic therapy. They assessed that hospital LOS was shorter for patients prescribed standard-dose systemic corticosteroids and who use guideline-recommended systemic corticosteroid and antibiotic therapy is recommended for hospitalized patients with COPD exacerbation.

Differential expression of tool-like receptors on eosinophils and their association with pathogen molecular patterns suggest different regulatory eosinophil phenotypes, which can vary according to the stimulus applied. Linch et al [77] showed 
that mouse eosinophils possess antibacterial properties against Pseudomonas aeruginosa bacterial infection. Furthermore, Eltboli et al [78] assessed that COPD exacerbation frequency and severity are associated with impaired macrophage efferocytosis of eosinophils.

In COPD exacerbations, a microbiota analysis has demonstrated overrepresentation of Firmicutes associated with eosinophilic exacerbation, compared to the predominance of Proteobacteria in exacerbations showing positive cultures for bacteria [51]. The Proteobacteria/Firmicutes ratio notably decreased in eosinophilic groups during exacerbation [51]. Interestingly, Kolsum et al showed an inverse relationship between eosinophil counts in COPD and bacterial infection of Hemophilus influenzae, Moraxella catarrhalis and Streptococcus pneumoniae, which are potentially pathogenic microorganisms [79]. The different expression of airway microbiota between eosinophilic and non-eosinophilic patients with both stable and exacerbation COPD further suggests the implication of these mechanisms in the pathogenesis of the disease. The decrement in blood eosinophils during COPD exacerbation with bacterial presence may also be an important determinant of individual response to corticosteroids [79]. As mentioned before, the use of inhaled corticosteroids for exacerbation COPD treatment is greatly discussed and controversial. The first association between corticosteroid administration and airway eosinophil response to treatment was seen in chronic bronchitis in 1978 [80]. Other clinical trials in COPD have shown that patients with increased eosinophil cells had a better response to corticosteroid treatment compared to those with limited numbers [81-83]; in particular, this finding was seen when airway eosinophil levels were greater than $2 \%$ in exacerbation [84]. Since it seems that inhaled corticosteroids have not shown benefit in COPD exacerbation patients and because of safety concerns on the long-term use of inhaled corticosteroids, elucidation of the eosinophil role in exacerbation of COPD should be largely assessed. Several studies showed no effects of this therapy in reducing lung decline, exacerbation, and mortality [85-89]. In addition, the WISDOM study showed no reduction in the time of exacerbation between patients treated with inhaled corticosteroids and patients treated without it [90], although the group treated with inhaled corticosteroids was associated with lung function decline at the end of the study. Furthermore, low eosinophil levels were predictive of worsened outcomes in COPD exacerbation [91, 92]. Sputum eosinophilia is associated with a positive response to stable COPD treated with corticosteroids [80, 81, 93] and the count of these immune cells can be used as a marker to monitor the reduction of COPD exacerbation during corticosteroid treatment.

These findings led to assessing that the circulating eosinophils in stable diseases can be used in predicting the risk of exacerbation and those counted in exacerbation can be used in predicting worsened outcomes and response to corticosteroids [94].

\section{Possible Role of Probiotics in Augmenting Treatment Response}

There is an urgent need to assess whether the manipulation of the lung microbiota may correct the dysbiosis associated with poor clinical outcomes. A possible change in microbiota can be the eradication of key pathogens, the modification of the lifestyle, including diet, cigarette smoking, drugs and/or the use of probiotics.

Evidence reveals that influenza infection and the use of antibiotics can disrupt gut microbiota leading to a reduction in Lactobacillus and Lactococcus, and an outgrowth of Enterobacteriaceae. This injury was induced by Th17 cells and IL-17 neutralization $[53,95]$. In addition, the prolonged use of corticosteroids alters the microbiota equilibrium, leading to an inflammation process and gut atherosclerosis [96, 97].

It is possible that the same mechanisms that cause inflammation and atherosclerosis in the intestine intervene in the lung. Notably, intestinal symptoms of COPD include malabsorption and inflammation that are further exacerbated with disease progression and severity [98, 99].

We also know that modulation of gut microbiota using probiotics is a usual and accepted method for restoring intestinal flora. This latter medical procedure has been shown to increase both the abundance of B cells expressing IgA in the lymph nodes and colon and the lymph node $\mathrm{T}$ follicular helper (TFH) cells. In addition, it increases IL-23-expressing dendritic cells. All changes are likely to improve host defence [100].

Lactobacillus is often overlooked in the lung microbiota, associated with anti-inflammatory effects in COPD [101] and protection against viral infections [102]. Sequencing-based studies of tissue from patients with COPD have demonstrated increasing Firmicutes community in severe disease linked with an increase in the Lactobacillus genus [103]. Interestingly, human macrophages can phagocytose Lactobacillus species, reducing cigarette smoking-related inflammation, suggesting that these species have a beneficial effect on smoking-related lung disease, such as COPD [101]. Tomosada et al have modulated the anti-viral response within the lungs of animal models infected with a respiratory syncytial virus (RSV) by the administration of Lactobacillus rhamnosus species prior to infection [104]. Thus, changes in the microbiota represent a way forward to protect the lung from respiratory viral infection.

\section{Conclusions and Future Directions}

The recent important advance in immunology research has been the recognition of the presence of millions of commensal bacteria, called "microbiota", not only in known tissue districts such as vaginal environment, skin, and gut, but also in the lungs. This microbial community is important for metabolism, nutrition, epithelial homeostasis and defence against foreign pathogens $[39,105]$. Dysbiosis of the resident microbiota has been associated with numerous disorders including cancer, respiratory and cardiovascular diseases as well as obesity [35-39]. There could be different variables that affect the lung microbiota, such as bacterial composition, host immune response, lifestyle, diet, cigarette smoking and the use of antibiotics and corticosteroids that are the standard therapy for COPD exacerbations.

The microbial flora of the respiratory tract in healthy sub- 
jects contains phylogenetically diverse species such as Firmicutes, Bacteroidetes, and Proteobacteria as most frequent phyla [44] and low presence of potentially pathogenic microorganisms, such as Hemophilus influenzae. During lung disease, the microbiota changes to a restricted flora that shows the prevalence of the Proteobacteria species, which include most of the potential pathogen micro-organisms, paralleled with a decline of Firmicutes [47]. These changes greatly disrupt the continuity of the bacterial pattern observed from the oropharynx to the bronchial tree, concurrently with the severity of the disease, as is demonstrated by the inverse correlation between Firmicutes and Proteobacteria relative abundance.

This situation is quite different in exacerbations, a condition that seems to be associated with lower microbial diversity, with an increment of phylum Proteobacteria $[60,106]$ and an increased proliferation of Moraxella catarrhalis. This latter species was positively correlated with the percentage of sputum neutrophils [51], consistently with its presence found in COPD exacerbation, which enhances airway inflammation by triggering neutrophils [107].

Hemophilus influenzae is known to produce biofilms protecting itself from the host immune system and antibiotics. This behaviour may explain its persistence after antibiotic treatments and may suggest the importance of adapting a new therapeutic approach. Moraxella catarrhalis and Pseudomonas aeruginosa can also form a biofilm that confers them the antibiotic resistance. This knowledge may also support the hypothesis to use vaccines or targeted antibacterial drug against these pathogens in order to prevent lung microbiota disruption.

A reduction of microbiota diversity and an increment of Proteobacteria/Firmicutes ratio in subjects treated with corticosteroids alone and the reversed trend seen in patients who received antibiotics support that the current standard of care therapy for COPD exacerbations can alter the lung microbiota. In agreement with previous reports on the limited efficacy and the higher side-effects of steroids [108, 109], it is also probable that corticosteroid treatment alone could potentially affect the lung microbiota. Furthermore, treatment with steroids may negatively influence the eosinophilic inflammation in COPD exacerbation that could be considered as a potential biomarker for identifying subgroups of patients who may respond to therapy, blocking what is called precision medicine (i.e. blood eosinophil-guided prednisolone therapy) [51, 84].

The possibilities for grouping patients by specific phenotypes could yield distinct microbiota population and the probabilities of repeating that type of COPD exacerbation [6].

In summary, treatment during exacerbations influences the lung microbiota differentially if based on antibiotic use, which reduces the bacterial abundance, especially that of Proteobacteria, or use or corticosteroids, which when administered systematically as a single treatment do not influence microbial richness but trigger the predominance of specific taxa from the Proteobacteria species [52, 60].

Understanding the causes and consequences of lung dysbiosis may influence the clinician's choice of adequate therapy, especially for exacerbations. All these results suggest that the lung microbiota is critical to COPD disease and that manipulation of these microbial patterns may be an attractive new tool for future treatments in preventing exacerbations. This ma- nipulation may be achieved with the use of probiotics, such as Lactobacillus or Bifidobacterium species, or by directly influencing the diet.

\section{Acknowledgments}

None to declare.

\section{Financial Disclosure}

The authors declare that they do not have a financial relationship with any commercial entity that has an interest in the subject of this manuscript.

\section{Conflict of Interest}

The authors declare that they do not have a conflict of interest.

\section{Author Contributions}

Both authors participated in review. They were involved in writing and revising the article prior to submission.

\section{References}

1. World Health Organization (WHO). The global burden of disease: 2004 update Geneva, Switzerland. 2008.

2. Yang IV, Schwartz DA. Epigenetic control of gene expression in the lung. Am J Respir Crit Care Med. 2011;183(10):1295-1301.

3. Lundback B, Lindberg A, Lindstrom M, Ronmark E, Jonsson AC, Jonsson E, Larsson LG, et al. Not 15 but 50\% of smokers develop COPD? - Report from the obstructive lung disease in Northern Sweden Studies. Respir Med. 2003;97(2):115-122.

4. Roca J, Vargas C, Cano I, Selivanov V, Barreiro E, Maier D, Falciani F, et al. Chronic Obstructive Pulmonary Disease heterogeneity: challenges for health risk assessment, stratification and management. J Transl Med. 2014;12(Suppl 2):S3.

5. Agusti A, Calverley PM, Celli B, Coxson HO, Edwards LD, Lomas DA, MacNee W, et al. Characterisation of COPD heterogeneity in the ECLIPSE cohort. Respir Res. 2010;11:122.

6. Mayhew D, Devos N, Lambert C, Brown JR, Clarke SC, Kim VL, Magid-Slav M, et al. Longitudinal profiling of the lung microbiome in the AERIS study demonstrates repeatability of bacterial and eosinophilic COPD exacerbations. Thorax. 2018;73(5):422-430.

7. Sethi S, Murphy TF. Infection in the pathogenesis and course of chronic obstructive pulmonary disease. N Engl J Med. 2008;359(22):2355-2365.

8. Papi A, Bellettato CM, Braccioni F, Romagnoli M, Caso- 
lari P, Caramori G, Fabbri LM, et al. Infections and airway inflammation in chronic obstructive pulmonary disease severe exacerbations. Am J Respir Crit Care Med. 2006;173(10):1114-1121.

9. Bafadhel M, McKenna S, Terry S, Mistry V, Reid C, Haldar P, McCormick M, et al. Acute exacerbations of chronic obstructive pulmonary disease: identification of biologic clusters and their biomarkers. Am J Respir Crit Care Med. 2011;184(6):662-671.

10. Burge S, Wedzicha JA. COPD exacerbations: definitions and classifications. Eur Respir J Suppl. 2003;41:46s-53s.

11. Celli BR, Barnes PJ. Exacerbations of chronic obstructive pulmonary disease. Eur Respir J. 2007;29(6):1224-1238.

12. Beghe B, Verduri A, Roca M, Fabbri LM. Exacerbation of respiratory symptoms in COPD patients may not be exacerbations of COPD. Eur Respir J. 2013;41(4):993-995.

13. Baraldo S, Turato G, Saetta M. Pathophysiology of the small airways in chronic obstructive pulmonary disease. Respiration. 2012;84(2):89-97.

14. Di Stefano A, Turato G, Maestrelli P, Mapp CE, Ruggieri MP, Roggeri A, Boschetto P, et al. Airflow limitation in chronic bronchitis is associated with T-lymphocyte and macrophage infiltration of the bronchial mucosa. Am J Respir Crit Care Med. 1996;153(2):629-632.

15. Hogg JC, Chu F, Utokaparch S, Woods R, Elliott WM, Buzatu L, Cherniack RM, et al. The nature of small-airway obstruction in chronic obstructive pulmonary disease. N Engl J Med. 2004;350(26):2645-2653.

16. Dickson RP, Huffnagle GB. The Lung Microbiome: New Principles for Respiratory Bacteriology in Health and Disease. PLoS Pathog. 2015;11(7):e1004923.

17. Sethi S, Evans N, Grant BJ, Murphy TF. New strains of bacteria and exacerbations of chronic obstructive pulmonary disease. N Engl J Med. 2002;347(7):465-471.

18. Fabbri LM, Luppi F, Beghe B, Rabe KF. Complex chronic comorbidities of COPD. Eur Respir J. 2008;31(1):204212.

19. Zhou A, Zhou Z, Zhao Y, Chen P. The recent advances of phenotypes in acute exacerbations of COPD. Int J Chron Obstruct Pulmon Dis. 2017;12:1009-1018.

20. Wedzicha JA, Donaldson GC. Exacerbations of chronic obstructive pulmonary disease. Respir Care. 2003;48(12):1204-1213; discussion 1213-1205.

21. Rohde G, Borg I, Wiethege A, Kauth M, Jerzinowski S, An Duong Dinh T, Bauer TT, et al. Inflammatory response in acute viral exacerbations of COPD. Infection. 2008;36(5):427-433.

22. Garcha DS, Thurston SJ, Patel AR, Mackay AJ, Goldring JJ, Donaldson GC, McHugh TD, et al. Changes in prevalence and load of airway bacteria using quantitative PCR in stable and exacerbated COPD. Thorax. 2012;67(12):1075-1080.

23. Dimopoulos G, Lerikou M, Tsiodras S, Chranioti A, Perros E, Anagnostopoulou U, Armaganidis A, et al. Viral epidemiology of acute exacerbations of chronic obstructive pulmonary disease. Pulm Pharmacol Ther. 2012;25(1):12-18.

24. Woodhead M, Blasi F, Ewig S, Garau J, Huchon G, Ieven $\mathrm{M}$, Ortqvist A, et al. Guidelines for the management of adult lower respiratory tract infections - full version. Clin Microbiol Infect. 2011;17(Suppl 6):E1-59.

25. Pauwels RA, Buist AS, Calverley PM, Jenkins CR, Hurd SS, Committee GS. Global strategy for the diagnosis, management, and prevention of chronic obstructive pulmonary disease. NHLBI/WHO Global Initiative for Chronic Obstructive Lung Disease (GOLD) Workshop summary. Am J Respir Crit Care Med. 2001;163(5):12561276.

26. Gao P, Zhang J, He X, Hao Y, Wang K, Gibson PG. Sputum inflammatory cell-based classification of patients with acute exacerbation of chronic obstructive pulmonary disease. PLoS One. 2013;8(5):e57678.

27. Anthonisen NR, Manfreda J, Warren CP, Hershfield ES, Harding GK, Nelson NA. Antibiotic therapy in exacerbations of chronic obstructive pulmonary disease. Ann Intern Med. 1987;106(2):196-204.

28. Donaldson GC, Seemungal TA, Patel IS, Bhowmik A, Wilkinson TM, Hurst JR, Maccallum PK, et al. Airway and systemic inflammation and decline in lung function in patients with COPD. Chest. 2005;128(4):1995-2004.

29. Bhowmik A, Seemungal TA, Sapsford RJ, Wedzicha JA. Relation of sputum inflammatory markers to symptoms and lung function changes in COPD exacerbations. Thorax. 2000;55(2):114-120.

30. Seemungal TA, Wilkinson TM, Hurst JR, Perera WR, Sapsford RJ, Wedzicha JA. Long-term erythromycin therapy is associated with decreased chronic obstructive pulmonary disease exacerbations. Am J Respir Crit Care Med. 2008;178(11):1139-1147.

31. Garcia-Aymerich J, Farrero E, Felez MA, Izquierdo J, Marrades RM, Anto JM, Estudi del Factors de Risc d'Aguditzacio de la Mi. Risk factors of readmission to hospital for a COPD exacerbation: a prospective study. Thorax. 2003;58(2):100-105.

32. Soler-Cataluna JJ, Rodriguez-Roisin R. Frequent chronic obstructive pulmonary disease exacerbators: how much real, how much fictitious? COPD. 2010;7(4):276-284.

33. Ferguson GT, Anzueto A, Fei R, Emmett A, Knobil K, Kalberg C. Effect of fluticasone propionate/salmeterol (250/50 microg) or salmeterol (50 microg) on COPD exacerbations. Respir Med. 2008;102(8):1099-1108.

34. Lederberg J, McCray AT. Ome Sweet Omics - a genealogical treasury of words. Scientist. 2001;15:8.

35. Frank DN, St Amand AL, Feldman RA, Boedeker EC, Harpaz N, Pace NR. Molecular-phylogenetic characterization of microbial community imbalances in human inflammatory bowel diseases. Proc Natl Acad Sci U S A. 2007;104(34):13780-13785.

36. Human Microbiome Project C. A framework for human microbiome research. Nature. 2012;486(7402):215-221.

37. Human Microbiome Project C. Structure, function and diversity of the healthy human microbiome. Nature. 2012;486(7402):207-214.

38. Hui AW, Lau HW, Chan TH, Tsui SK. The human microbiota: a new direction in the investigation of thoracic diseases. J Thorac Dis. 2013;5(Suppl 2):S127-131.

39. Tulic MK, Piche T, Verhasselt V. Lung-gut cross-talk: evidence, mechanisms and implications for the mucosal in- 
flammatory diseases. Clin Exp Allergy. 2016;46(4):519528.

40. Rosell A, Monso E, Soler N, Torres F, Angrill J, Riise $\mathrm{G}$, Zalacain R, et al. Microbiologic determinants of exacerbation in chronic obstructive pulmonary disease. Arch Intern Med. 2005;165(8):891-897.

41. Laurenzi GA, Potter RT, Kass EH. Bacteriologic flora of the lower respiratory tract. N Engl J Med. 1961;265:12731278.

42. Hilty M, Burke C, Pedro H, Cardenas P, Bush A, Bossley $\mathrm{C}$, Davies J, et al. Disordered microbial communities in asthmatic airways. PLoS One. 2010;5(1):e8578.

43. Dickson RP, Erb-Downward JR, Martinez FJ, Huffnagle GB. The Microbiome and the respiratory tract. Annu Rev Physiol. 2016;78:481-504.

44. Erb-Downward JR, Thompson DL, Han MK, Freeman CM, McCloskey L, Schmidt LA, Young VB, et al. Analysis of the lung microbiome in the "healthy" smoker and in COPD. PLoS One. 2011;6(2):e16384.

45. Dickson RP, Erb-Downward JR, Huffnagle GB. The role of the bacterial microbiome in lung disease. Expert Rev Respir Med. 2013;7(3):245-257.

46. Wu H, Kuzmenko A, Wan S, Schaffer L, Weiss A, Fisher JH, Kim KS, et al. Surfactant proteins A and D inhibit the growth of Gram-negative bacteria by increasing membrane permeability. J Clin Invest. 2003;111(10):15891602.

47. Garcia-Nunez M, Millares L, Pomares X, Ferrari R, PerezBrocal V, Gallego M, Espasa M, et al. Severity-related changes of bronchial microbiome in chronic obstructive pulmonary disease. J Clin Microbiol. 2014;52(12):42174223.

48. Monso E, Ruiz J, Rosell A, Manterola J, Fiz J, Morera J, Ausina V. Bacterial infection in chronic obstructive pulmonary disease. A study of stable and exacerbated outpatients using the protected specimen brush. Am J Respir Crit Care Med. 1995;152(4 Pt 1):1316-1320.

49. Soler N, Torres A, Ewig S, Gonzalez J, Celis R, El-Ebiary $\mathrm{M}$, Hernandez $\mathrm{C}$, et al. Bronchial microbial patterns in severe exacerbations of chronic obstructive pulmonary disease (COPD) requiring mechanical ventilation. Am J Respir Crit Care Med. 1998;157(5 Pt 1):1498-1505.

50. Ball P. Epidemiology and treatment of chronic bronchitis and its exacerbations. Chest. 1995;108(2 Suppl):43S$52 \mathrm{~S}$.

51. Wang Z, Bafadhel M, Haldar K, Spivak A, Mayhew D, Miller BE, Tal-Singer R, et al. Lung microbiome dynamics in COPD exacerbations. Eur Respir J. 2016;47(4):10821092.

52. Dy R, Sethi S. The lung microbiome and exacerbations of COPD. Curr Opin Pulm Med. 2016;22(3):196-202.

53. O'Dwyer DN, Dickson RP, Moore BB. The lung microbiome, immunity, and the pathogenesis of chronic lung disease. J Immunol. 2016;196(12):4839-4847.

54. Jaspers I. Cigarette smoke effects on innate immune mechanisms in the nasal mucosa. Potential effects on the microbiome. Ann Am Thorac Soc. 2014;11(Suppl 1):S3842.

55. Heijink IH, Brandenburg SM, Postma DS, van Ooster- hout AJ. Cigarette smoke impairs airway epithelial barrier function and cell-cell contact recovery. Eur Respir J. 2012;39(2):419-428.

56. Rutten EPA, Lenaerts K, Buurman WA, Wouters EFM. Disturbed intestinal integrity in patients with COPD: effects of activities of daily living. Chest. 2014;145(2):245252.

57. Davies L, Angus RM, Calverley PM. Oral corticosteroids in patients admitted to hospital with exacerbations of chronic obstructive pulmonary disease: a prospective randomised controlled trial. Lancet. 1999;354(9177):456460.

58. Walters JA, Gibson PG, Wood-Baker R, Hannay M, Walters EH. Systemic corticosteroids for acute exacerbations of chronic obstructive pulmonary disease. In: Walters JA, editor. Cochrane Database of Systematic Reviews. Chichester, UK: John Wiley \& Sons, Ltd; 2009. p. CD001288.

59. Niewoehner DE, Erbland ML, Deupree RH, Collins D, Gross NJ, Light RW, Anderson P, et al. Effect of systemic glucocorticoids on exacerbations of chronic obstructive pulmonary disease. Department of Veterans Affairs Cooperative Study Group. N Engl J Med. 1999;340(25):19411947.

60. Huang YJ, Sethi S, Murphy T, Nariya S, Boushey HA, Lynch SV. Airway microbiome dynamics in exacerbations of chronic obstructive pulmonary disease. J Clin Microbiol. 2014;52(8):2813-2823.

61. Albert RK, Connett J, Bailey WC, Casaburi R, Cooper JA, Jr., Criner GJ, Curtis JL, et al. Azithromycin for prevention of exacerbations of COPD. N Engl J Med. 2011;365(8):689-698.

62. Nouira S, Marghli S, Belghith M, Besbes L, Elatrous S, Abroug F. Once daily oral ofloxacin in chronic obstructive pulmonary disease exacerbation requiring mechanical ventilation: a randomised placebo-controlled trial. Lancet. 2001;358(9298):2020-2025.

63. Vollenweider DJ, Jarrett H, Steurer-Stey CA, GarciaAymerich J, Puhan MA. Antibiotics for exacerbations of chronic obstructive pulmonary disease. Cochrane Database Syst Rev. 2012;12:CD010257.

64. Buffie CG, Bucci V, Stein RR, McKenney PT, Ling L, Gobourne A, No D, et al. Precision microbiome reconstitution restores bile acid mediated resistance to Clostridium difficile. Nature. 2015;517(7533):205-208.

65. Elrich P. Uber die specifischen granulationen des blutes. Arch Anat Physiol. 1879;3:571-579.

66. Chu DK, Jimenez-Saiz R, Verschoor CP, Walker TD, Goncharova S, Llop-Guevara A, Shen P, et al. Indigenous enteric eosinophils control DCs to initiate a primary Th2 immune response in vivo. J Exp Med. 2014;211(8):16571672.

67. Muller E. Localization of eosinophils in the thymus by the peroxidase reaction. Histochemistry. 1977;52(3):273279.

68. Rosenberg HF, Dyer KD, Foster PS. Eosinophils: changing perspectives in health and disease. Nat Rev Immunol. 2013;13(1):9-22.

69. Rutgers SR, Timens W, Kaufmann HF, van der Mark TW, Koeter GH, Postma DS. Comparison of induced sputum 
with bronchial wash, bronchoalveolar lavage and bronchial biopsies in COPD. Eur Respir J. 2000;15(1):109115.

70. Wardlaw AJ. Molecular basis for selective eosinophil trafficking in asthma: A multistep paradigm. J Allergy Clin Immunol. 1999;104(5):917-926.

71. Spencer LA, Weller PF. Eosinophils and Th2 immunity: contemporary insights. Immunol Cell Biol. 2010;88(3):250-256.

72. Hallstrand TS, Henderson WR, Jr. An update on the role of leukotrienes in asthma. Curr Opin Allergy Clin Immunol. 2010;10(1):60-66.

73. Zhu J, Bandi V, Qiu S, Figueroa DJ, Evans JF, Barnes N, Guntupalli KK, et al. Cysteinyl leukotriene 1 receptor expression associated with bronchial inflammation in severe exacerbations of COPD. Chest. 2012;142(2):347-357.

74. Sivapalan P, Lapperre TS, Janner J, Laub RR, Moberg M, Bech CS, Eklof J, et al. Eosinophil-guided corticosteroid therapy in patients admitted to hospital with COPD exacerbation (CORTICO-COP): a multicentre, randomised, controlled, open-label, non-inferiority trial. Lancet Respir Med. 2019;7(8):699-709.

75. Xue J, Cui YN, Chen P, Cai S, Chen L, Dai ZS, Chen Y. [Blood eosinophils: a biomarker of response to glucocorticoids and increased readmissions in severe hospitalized exacerbations of COPD]. Zhonghua Jie $\mathrm{He} \mathrm{He} \mathrm{Hu} \mathrm{Xi} \mathrm{Za}$ Zhi. 2019;42(6):426-431.

76. Petite SE, Murphy JA. Systemic corticosteroid and antibiotic use in hospitalized patients with chronic obstructive pulmonary disease exacerbation. Ann Pharmacother. 2019;53(2):144-150.

77. Linch SN, Kelly AM, Danielson ET, Pero R, Lee JJ, Gold JA. Mouse eosinophils possess potent antibacterial properties in vivo. Infect Immun. 2009;77(11):4976-4982.

78. Eltboli O, Bafadhel M, Hollins F, Wright A, Hargadon B, Kulkarni N, Brightling C. COPD exacerbation severity and frequency is associated with impaired macrophage efferocytosis of eosinophils. BMC Pulm Med. 2014; $14: 112$.

79. Kolsum U, Donaldson GC, Singh R, Barker BL, Gupta V, George L, Webb AJ, et al. Blood and sputum eosinophils in COPD; relationship with bacterial load. Respir Res. 2017;18(1):88.

80. Shim C, Stover DE, Williams MH, Jr. Response to corticosteroids in chronic bronchitis. J Allergy Clin Immunol. 1978;62(6):363-367.

81. Pizzichini E, Pizzichini MM, Gibson P, Parameswaran K, Gleich GJ, Berman L, Dolovich J, et al. Sputum eosinophilia predicts benefit from prednisone in smokers with chronic obstructive bronchitis. Am J Respir Crit Care Med. 1998;158(5 Pt 1):1511-1517.

82. Leigh R, Pizzichini MM, Morris MM, Maltais F, Hargreave FE, Pizzichini E. Stable COPD: predicting benefit from high-dose inhaled corticosteroid treatment. Eur Respir J. 2006;27(5):964-971.

83. Brightling CE, McKenna S, Hargadon B, Birring S, Green R, Siva R, Berry M, et al. Sputum eosinophilia and the short term response to inhaled mometasone in chronic obstructive pulmonary disease. Thorax. 2005;60(3):193-
198.

84. Bafadhel M, McKenna S, Terry S, Mistry V, Pancholi M, Venge P, Lomas DA, et al. Blood eosinophils to direct corticosteroid treatment of exacerbations of chronic obstructive pulmonary disease: a randomized placebo-controlled trial. Am J Respir Crit Care Med. 2012;186(1):4855.

85. Calverley PM, Anderson JA, Celli B, Ferguson GT, Jenkins C, Jones PW, Yates JC, et al. Salmeterol and fluticasone propionate and survival in chronic obstructive pulmonary disease. N Engl J Med. 2007;356(8):775-789.

86. Singh D, Papi A, Corradi M, Pavlisova I, Montagna I, Francisco C, Cohuet G, et al. Single inhaler triple therapy versus inhaled corticosteroid plus long-acting beta2-agonist therapy for chronic obstructive pulmonary disease (TRILOGY): a double-blind, parallel group, randomised controlled trial. Lancet. 2016;388(10048):963-973.

87. Calverley PM, Walker P. Chronic obstructive pulmonary disease. Lancet. 2003;362(9389):1053-1061.

88. Calverley PM, Boonsawat W, Cseke Z, Zhong N, Peterson $\mathrm{S}$, Olsson $\mathrm{H}$. Maintenance therapy with budesonide and formoterol in chronic obstructive pulmonary disease. Eur Respir J. 2003;22(6):912-919.

89. Vestbo J, Anderson JA, Brook RD, Calverley PM, Celli BR, Crim C, Martinez F, et al. Fluticasone furoate and vilanterol and survival in chronic obstructive pulmonary disease with heightened cardiovascular risk (SUMMIT): a double-blind randomised controlled trial. Lancet. 2016;387(10030):1817-1826.

90. Magnussen H, Disse B, Rodriguez-Roisin R, Kirsten A, Watz H, Tetzlaff K, Towse L, et al. Withdrawal of inhaled glucocorticoids and exacerbations of COPD. N Engl J Med. 2014;371(14):1285-1294.

91. Holland M, Alkhalil M, Chandromouli S, Janjua A, Babores M. Eosinopenia as a marker of mortality and length of stay in patients admitted with exacerbations of chronic obstructive pulmonary disease. Respirology. 2010;15(1):165-167.

92. Steer J, Gibson J, Bourke SC. The DECAF Score: predicting hospital mortality in exacerbations of chronic obstructive pulmonary disease. Thorax. 2012;67(11):970976.

93. Brightling CE, Monteiro W, Ward R, Parker D, Morgan MD, Wardlaw AJ, Pavord ID. Sputum eosinophilia and short-term response to prednisolone in chronic obstructive pulmonary disease: a randomised controlled trial. Lancet. 2000;356(9240):1480-1485.

94. Bafadhel M, Pavord ID, Russell REK. Eosinophils in COPD: just another biomarker? Lancet Respir Med. 2017;5(9):747-759.

95. Wang J, Li F, Wei H, Lian ZX, Sun R, Tian Z. Respiratory influenza virus infection induces intestinal immune injury via microbiota-mediated Th17 cell-dependent inflammation. J Exp Med. 2014;211(12):2397-2410.

96. Poroyko VA, Carreras A, Khalyfa A, Khalyfa AA, Leone V, Peris E, Almendros I, et al. Chronic sleep disruption alters gut microbiota, induces systemic and adipose tissue inflammation and insulin resistance in mice. Sci Rep. 2016;6:35405. 
97. Moreno-Indias I, Torres M, Montserrat JM, Sanchez-A1coholado L, Cardona F, Tinahones FJ, Gozal D, et al. Intermittent hypoxia alters gut microbiota diversity in a mouse model of sleep apnoea. Eur Respir J. 2015;45(4):10551065 .

98. Beloborodova EI, Akimova LA, Burkovskaia BA, Asanova AV, Semenenko EV. [Activity of systemic inflammatory reaction in patients with chronic obstructive pulmonary disease in regard to small intestinal absorption function]. Ter Arkh. 2009;81(3):19-23.

99. Fedorova TA, Spirina L, Chernekhovskaia NE, Kanareitseva TD, Sotnikova TI, Zhidkova NV, Anchukova EL. [The stomach and duodenum condition in patients with chronic obstructive lung diseases]. Klin Med (Mosk). 2003;81(10):31-33.

100. Noverr MC, Noggle RM, Toews GB, Huffnagle GB. Role of antibiotics and fungal microbiota in driving pulmonary allergic responses. Infect Immun. 2004;72(9):4996-5003.

101. Mortaz E, Adcock IM, Ricciardolo FL, Varahram M, Jamaati H, Velayati AA, Folkerts G, et al. Anti-Inflammatory Effects of Lactobacillus Rahmnosus and Bifidobacterium Breve on Cigarette Smoke Activated Human Macrophages. PLoS One. 2015;10(8):e0136455.

102. Gabryszewski SJ, Bachar O, Dyer KD, Percopo CM, Killoran KE, Domachowske JB, Rosenberg HF. Lactobacillus-mediated priming of the respiratory mucosa protects against lethal pneumovirus infection. J Immunol. 2011;186(2):1151-1161.

103. Sze MA, Dimitriu PA, Hayashi S, Elliott WM, McDon- ough JE, Gosselink JV, Cooper J, et al. The lung tissue microbiome in chronic obstructive pulmonary disease. Am J Respir Crit Care Med. 2012;185(10):1073-1080.

104. Tomosada Y, Chiba E, Zelaya H, Takahashi T, Tsukida K, Kitazawa H, Alvarez S, et al. Nasally administered Lactobacillus rhamnosus strains differentially modulate respiratory antiviral immune responses and induce protection against respiratory syncytial virus infection. BMC Immunol. 2013;14:40.

105. Sommer F, Backhed F. The gut microbiota-masters of host development and physiology. Nat Rev Microbiol. 2013;11(4):227-238.

106. Millares L, Ferrari R, Gallego M, Garcia-Nunez M, Perez-Brocal V, Espasa M, Pomares X, et al. Bronchial microbiome of severe COPD patients colonised by Pseudomonas aeruginosa. Eur J Clin Microbiol Infect Dis. 2014;33(7):1101-1111.

107. Parameswaran GI, Wrona CT, Murphy TF, Sethi S. Moraxella catarrhalis acquisition, airway inflammation and protease-antiprotease balance in chronic obstructive pulmonary disease. BMC Infect Dis. 2009;9:178.

108. Leuppi JD, Schuetz P, Bingisser R, Bodmer M, Briel M, Drescher T, Duerring U, et al. Short-term vs conventional glucocorticoid therapy in acute exacerbations of chronic obstructive pulmonary disease: the REDUCE randomized clinical trial. JAMA. 2013;309(21):2223-2231.

109. McEvoy CE, Niewoehner DE. Adverse effects of corticosteroid therapy for COPD. A critical review. Chest. 1997;111(3):732-743. 